\title{
THE Modernization OF THE MUlTimotor Electric Drives
}

\section{Breido, J., Sivyakova, G. \& GuRUSHKin A.}

Abstract: Based on the modernization experience of multi-motor electric drives, unique technological lines and hoisting units. Implementation methodology for such projects was suggested. Their essence is in the combination of experimental studies in the normal operation of equipment and the physical simulation to obtain adequate mathematical models, as well as in the development of new systems in the normal and emergency modes. This technology is allowed to upgrade electric drives of unit continuous annealing and casting crane with hoisting capacity 420 tons of the JS "ArcelorMittal Temirtau". As a result, metal heat treatment increased velocity from 2,5 to $8 \mathrm{~m} / \mathrm{s}$ with a minimum dynamic loads in the strip. The imbalance of the moments was decreased to 1-2,5\% from $45 \%$ in static and $20 \%$ in dynamic for casting crane, and the crane productivity has doubled.

Key words: multi-motor electric drives, continuous annealing units, cranes foundry production, experience of the modernization
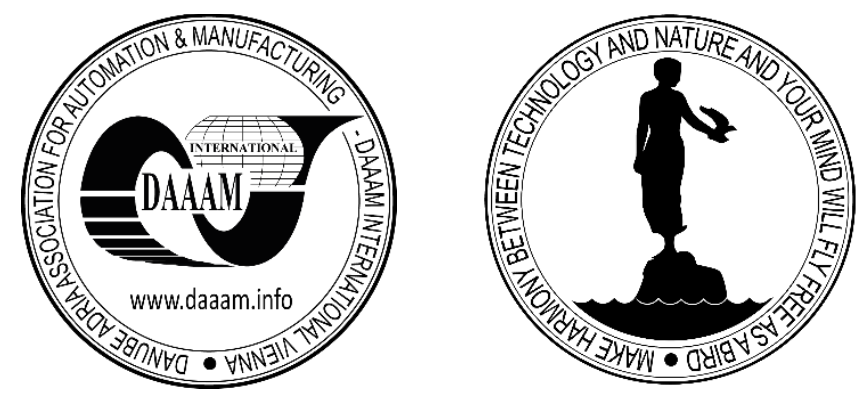

Authors' data: Univ. Prof., Dr. Techn. Sci. Breido, J[oseph]*; Cand. Techn. Sci. Sivyakova, G[alina]**; Cand. Techn.Sci. Gurushkin A[rtem]**; *Karaganda State Technical University, Mira blvd 56, 100027, Karaganda, Kazakhstan, **Karaganda State Industrial University, Republic av.30, 101400, Temirtau, Kazakhstan, jbreido@mail.ru,galina-siv@mail.ru, artem.gurushkin@mail.ru

This Publication has to be referred as: Breido, I[osif]; Sivyakova, G[alina] \& Gurushkin, A[rtem] (2016). The Modernization of the Multimotor Electric Drives, Chapter 34 in DAAAM International Scientific Book 2016, pp.375-392, B. Katalinic (Ed.), Published by DAAAM International, ISBN 978-3-902734-09-9, ISSN 17269687, Vienna, Austria

DOI: $10.2507 /$ daaam.scibook.2016.34 


\section{Introduction}

Electric drives of the rolling and temper mill (Borovik, 2010), papermaking machines, lines for the processing different materials, test stands of mechanical helicopters transmissions (Tarasov, 2008), foundry cranes and other mechanisms belong to multi-impellent interconnected electric drive systems. All of them constitute an automatic control systems of different variables (speed, tension, e.m.f., torque, and so on), connected to each other by different types of elastic connections in a complex system that performs of a single target function (Breido, 2013; Frederick \& Dubey, 1997).

A number of technical and organizational problems that do not allow fully use of well-known and proven methods and technologies parametric settings and adjustment of electromechanical systems, when upgrading such electromechanical systems, it is due to the following factors (Breido \& Gurushkin, 2009; Polyakov et al., 2009):

1) the inapplicability of analytical synthesis methods for multi-mass nonlinear systems (Breido et al., 2013);

2) the presence of the gap-formation, elastic or elastic-plastic connections, alternating tension and slack processes of working body (Polyakov et al., 2010);

3 ) the lack of reliable information on the quantitative values of elasticity and (or) plasticity of the material being processed, dissipation, value of gaps, damping coefficients, etc. (Breido et al., 2013);

4) the lack of positive results in the simulation without quantitative values of the parameters of electromechanical systems (Medvedev \& Kuznetsov, 2011);

5) the inadmissibility of long-term intervention in the continuous technological processes, which significantly complicates the setup steps and can lead to accidents and downtime (Breido, 2013).

On the other hand, there are built-in or additional subsystems that contain information from sensors of speed, effort or tension, as well as the unobserved variables in modern processing lines and unique processing units (torque, flux linkage, magnetic fluxes etc.) (Faizrakhmanov et al., 2015).

The authors suggested a methodology that provides the structural and parametric optimization of interconnected through the processed material or mechanical connections of multi-motor electric drives on the basis of modernization experience of the electric drives of the continuous annealing units used for annealing cold-rolled sheet steel, as well as the twin-engine electric drive mechanism of main hoist cranes by carrying capacity 420/100/20 tons there. Authors' developed methodology is to combine simulation and physical modeling with experimental researches carried out in the process of working modes in which a part of the parameters to produce adequate mathematical models of electromechanical systems. The obtained models are used for structural and parametric optimization as well as working out the basic technical solutions, including electric drives adjustment without removing the equipment from the technological process. 


\section{Modernization of interconnected multimotor drives of continuous annealing units}

Continuous annealing units (CAU) are used for the annealing of cold-rolled steel sheet at the largest metallurgical plants. Metal passes through the draw furnace of turret-type and under various conditions of heating and cooling during annealing, also local trip compression and line stretching are taken place.

There were long idle-hours most of which were due to the instability of the high speed mode and strip tension, leading to metal bleeding during the operation at the CAU on the JSC "ArcelorMittal Temirtau". Device start is accompanied by strong oscillating motion and displacement of the strip from the unit axis after stops. When design speed of the metal motion is up to $7,5 \mathrm{~m} / \mathrm{s}$, only speed $2-3 \mathrm{~m} / \mathrm{s}$ is achieved.

The objective of the interconnected CAU electric drives modernization was to increase the performance (metal strip speed of the movement) to the project level without modification of the power unit.

Functional scheme of the middle part of the CAU process, which determines the basic dynamic processes taking place in the strip during the heat treatment, is shown in Fig. 1. The main mechanisms are pinch rollers No3 (PR3) and No4 (PR4), tension adjuster (TA) and the vertical tower-type furnace (TF1-TF4) for the strip annealing (Breido, 2005). PR are designed for metal transportation. TA provides a strip tension.

$\mathrm{TF}$ is divided into four chambers providing heating, equalizing, controlled and accelerated metal cooling. Transportation of the strip in TF chambers is performed in groups by 15 rollers with individual electric drivers with capacity of $22 \mathrm{~kW}$ fed by the grouped SCR's controls for each chamber.

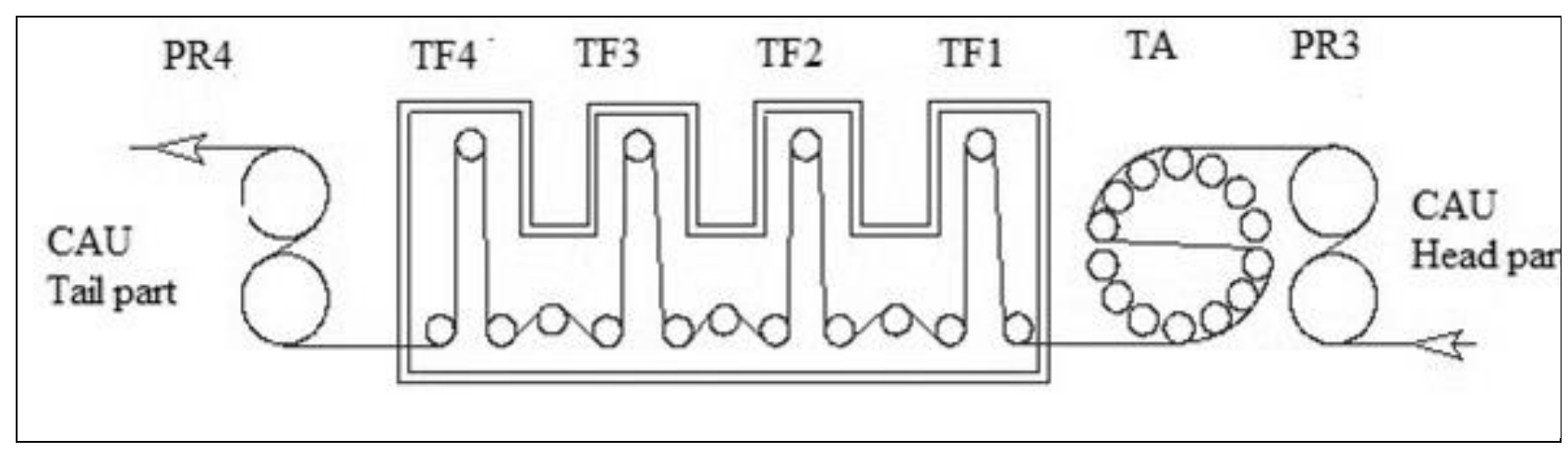

Fig. 1. Middle technological CAU part

ANO electric drives use DC motors with separate excitation. The automatic control system (ACS) TF is designed as double-braking speed control systems are intended to compensate the frictional losses in the strip. The rate of furnace rollers is synchronized with speed of the strip in the middle part of the unit. ACS PR are doublebraking and built by the method of subordinate regulation. The PR drivers have a capacity $37 \mathrm{~kW}$ and $55 \mathrm{~kW}$. A system of subordinate regulation of the upper roller motor excitation current is used to distribute the load between the upper and lower PR. Demand signal for the excitation current regulator is a signal proportional to the EMF. Single-braking ACS TA operates in current regulator mode. The motor with capacity $640 \mathrm{~kW}$ is used. 
Maintaining the constancy of the strip tension is the main task of control systems of the drives of the unit technological medium, for which modernization has been carried out.

The collection and analysis of information necessary for modernization is made including information from the in-process sensors of the strip tension on the first stage which placed in the TF tambours.

The oscillograms of the all standard working modes of electric drive units mechanisms were obtained, including drive-brake and steady state rating (Breido, 1998), which did not require undue experimentation influencing the operation of the line. A preliminary decomposition of the existing electromechanical structure was carried out with taking into account the possibilities of control parameters of the electromechanical system. The electric drivers, systems of mechanisms automatic control, converters and elementary sections of mechanical linkages were accepted as the basic elements in CAU. The information about electric drive rotation speed, currents, volt ages, input, intermediate and output signals of control systems, converters, as well as the information about strip tension is available in CAU. Oscillographic testing in each of the design modes is performed repeatedly (at least 6 times for each implementation).

The excitations were introduced alternatively by changing the control influences and the force distribution along the strip from the tension sensors was recorded to estimate the dynamic modes in the metal strip to the electric drives of TF in inching mode, when threading and metal strip stretching (Fig. 2a). It is established that the elastic deformation wave propagates not only in a forward, but also in backward direction (when propagating elastic wave in the direction of strip movement the attenuation of the dynamic forces does not take place, and against the strip movement the attenuation is $70-80 \%$ ). At the same time there was an increase in the amplitude of the force along the strip in the course of its movement, which was explained by an increase in the strip rigidity coefficient when reducing the heating temperature and its change during the passage of metal through different TF chambers (Zyuzin, 1991). The frequency spectrum of the force change is concentrated in the frequency range of 0,12,5 Hz. The forced and self-oscillations are presented in the strip. Forced oscillations contain components excited by the constant interaction of the rollers with the strip (their frequency is proportional to strip speed), as well as the components that arise when changing the speed. The time of the elastic waves propagation was $0,7 \mathrm{~s}$ in the course of strip, from the first to the third tambour, and 0,6 s - in the opposite direction. Also, it has been determined that it is necessary to take into account the elongations than appears due to the strip tension and the temperature influence (Vydrin, 1984).

The results of experiments and analysis of the CAU operating modes have shown that when designing the electric drives, it is not considered process of the movement of elastic wave deformation along the metal strip as along the course of movement as against it, as well as changes in its properties during annealing have not been taken into account. For this reason, we could not reach the estimated output. 


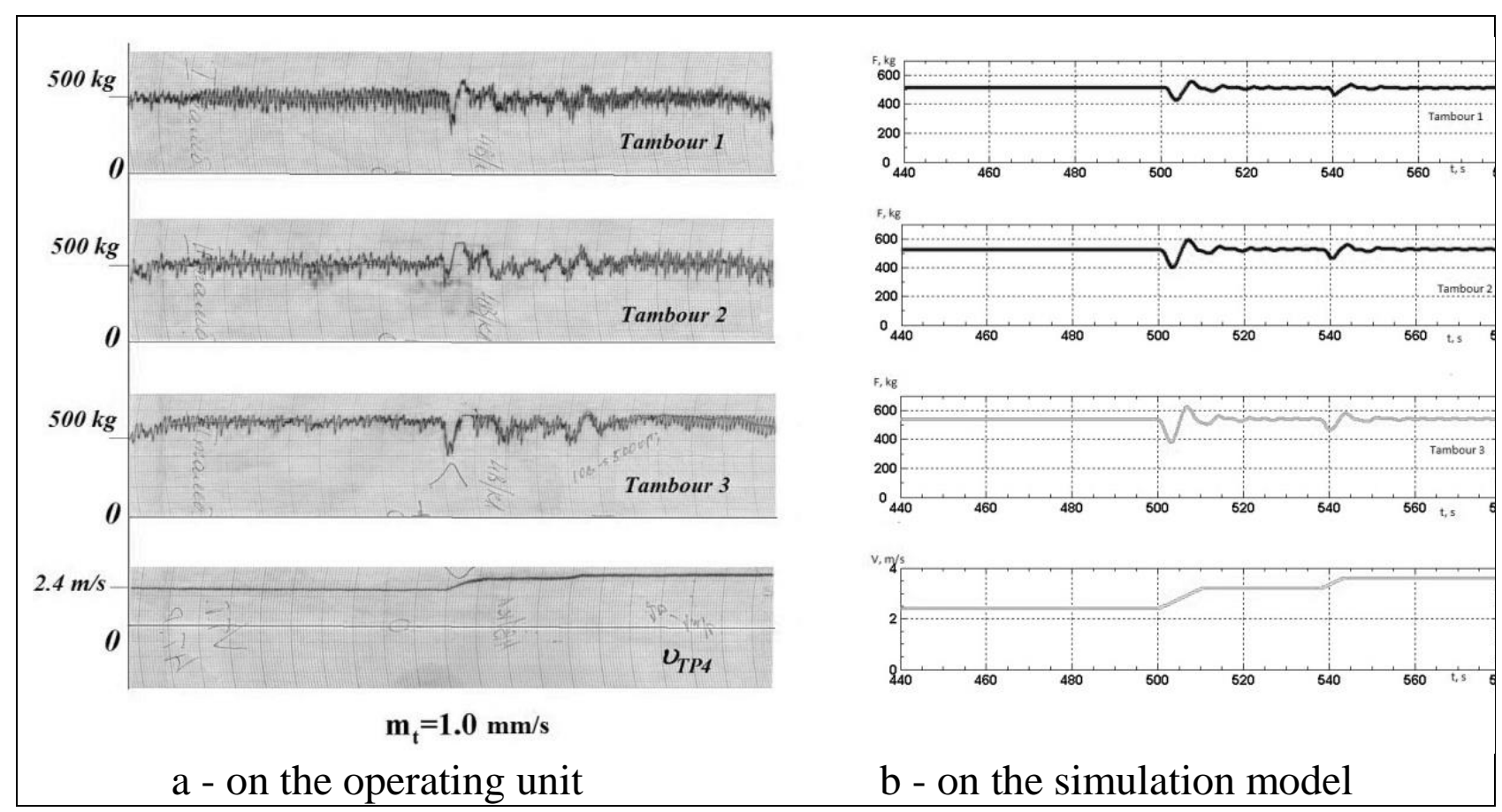

Fig. 2. Forces signals in the metal strip in the tower-type furnace chambers

Development of the mathematical model of electromechanical system CAU has been carried out on the second stage. Repeatability is typical for structural components of electric drives CAU. Therefore, decomposition method was used and the CAU model of the electric driver was represented by hierarchical structure (Fig. 3) while developing the simulation model.

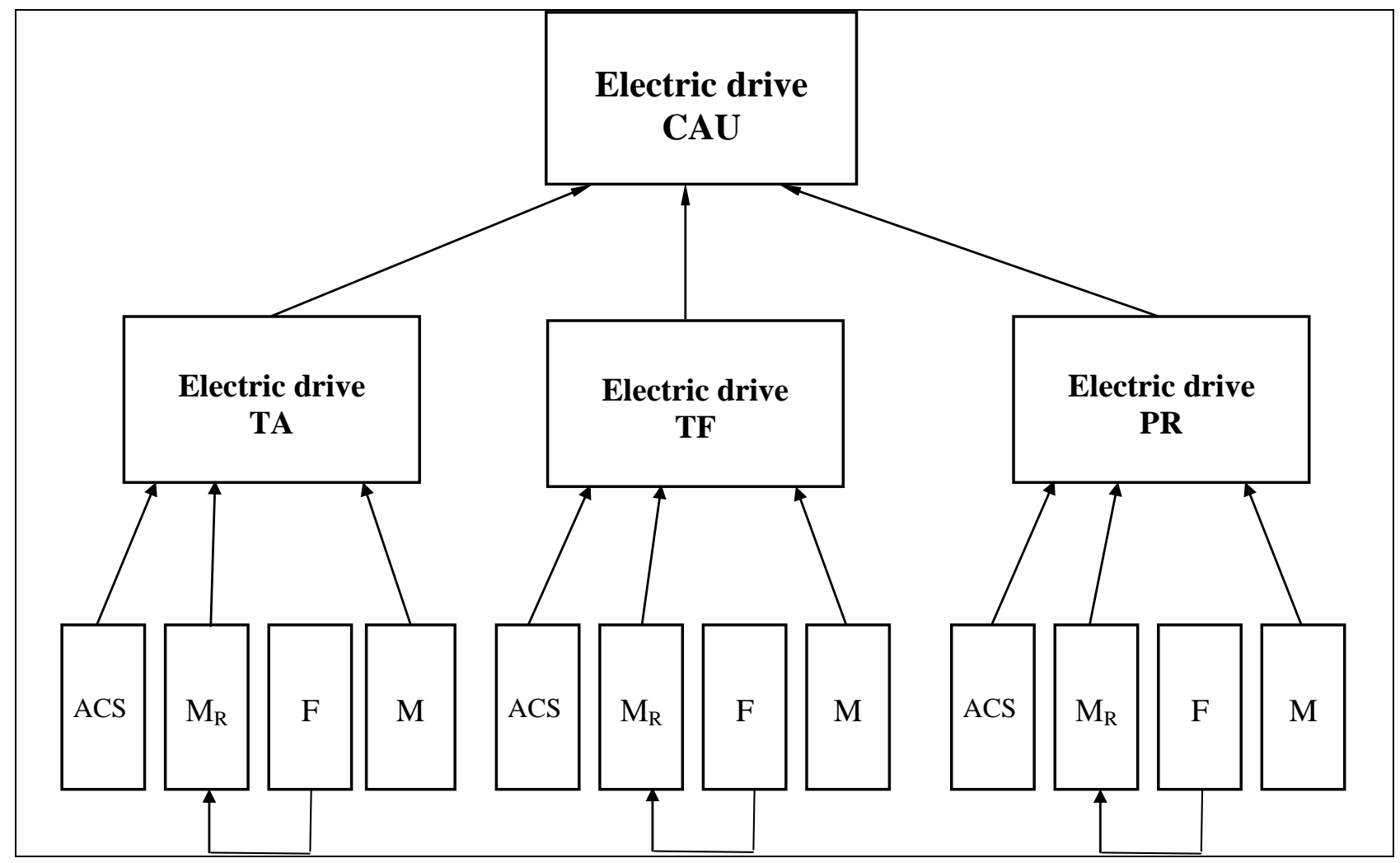

Fig. 3. The hierarchical structure of CAU electric drive 
The first level consists of elastic tension sub-model force in the strip $\mathrm{F}_{\mathrm{f}}$ resistance modulus $\mathrm{M}_{\mathrm{R}}$, electric drivers and ACS. They make up the sub-models of the second level such as models of TF. PR and TA electric drivers. At the second level, there are three types of subsystems and two of them (TF and PR) are similar. From four TF models, two PR models and TA model the model of the third level is collected, i. e. CAU electric driver model (Breido \& Sivyakova, 2008; Sivyakova, 2005; Breido, 2005).

Approximation of the model of metal strip is made by replacing the elements with distributed parameters of the multi-mass system with lumped masses and elastic elements of finite rigidity. Then multi-mass system was reduced to dual-mass with an accuracy of less than 5\% (Rassudov, 1987). Design scheme of CAU electromechanical system represented by a 13-mass system is shown in Fig. 4 where all interacting masses are designated by the order numbers in accordance with the direction of the strip movement in the unit.

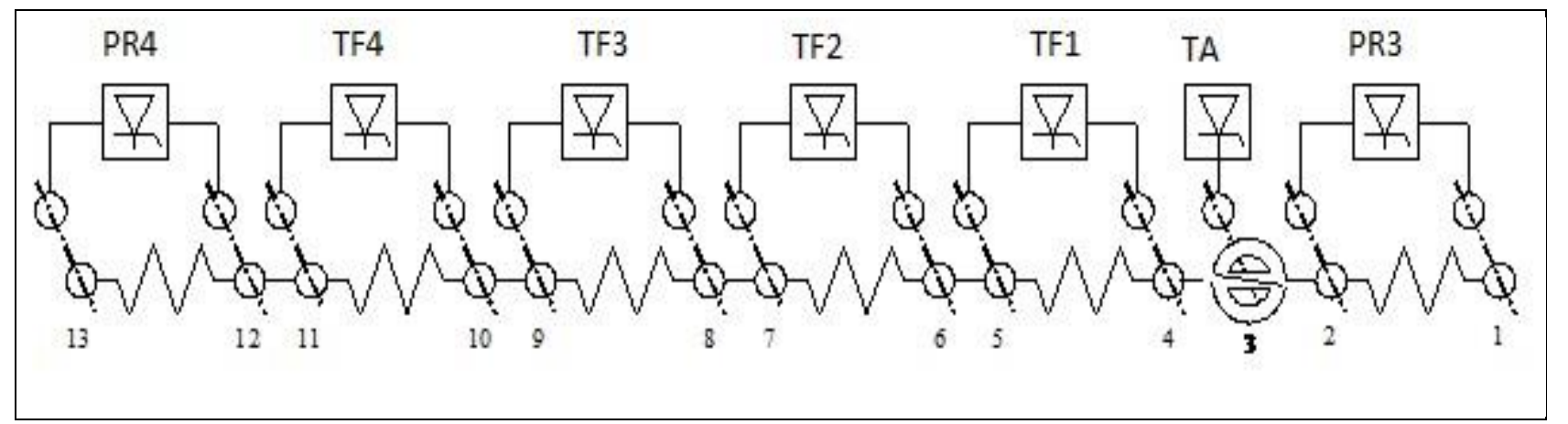

Fig. 4. The design scheme of CAU electromechanical system

Multimotor group electric drive of rollers in each of the tower-type furnace chambers (TF1-TF4) is replaced by the dual-motor equivalent. Equivalent to the TF electric drivers was performed by the following equations (Breido \& Sivyakova, 2008):

$$
\left.\begin{array}{l}
u_{a}=i_{a e q} \cdot R_{a e q}+L_{a e q} \frac{d i_{a e q}}{d t}+C_{t} \cdot \Phi \cdot \omega \\
J_{e q} \frac{d \omega}{d t}=M_{e q}-M_{r e q}
\end{array}\right\}
$$

where $i_{\text {aeq }}=m \cdot i$ - equivalent current, $A$;

$R_{a e q}=\mathrm{R}_{\Sigma \mathrm{a}} / \mathrm{m}$ - equivalent resistance of the armature circuit, $\mathrm{Ohm}$;

$\mathrm{L}_{\mathrm{aeq}}=\mathrm{L}_{\Sigma \mathrm{a}} \cdot \mathrm{m}$ - equivalent inductance of the armature circuit, Ohm;

$J_{e q}=J \cdot m$ - equivalent armatures inertia moment, $\mathrm{kg} \cdot \mathrm{m}^{2}$;

$\mathrm{M}_{\mathrm{eq}}=\mathrm{M}_{\mathrm{r}} \cdot \mathrm{m}$ equivalent torque moment, $\mathrm{H} \cdot \mathrm{M}$;

$\mathrm{M}_{\mathrm{eq}}=\mathrm{M}_{\mathrm{r}} \cdot \mathrm{m}$ - equivalent modulus of resistance, $\mathrm{H} \cdot \mathrm{M} ; \mathrm{m}$ - number of drivers that are replaced by one equivalent.

The equation of the resistance module of TF electric drivers has following form: 


$$
\left.M_{R}=\left(F_{j k}+F_{f}\right) \frac{r}{i}+K_{r e d} \cdot M_{R f k}+\frac{a \cdot n}{60}\right\}
$$

where $\mathrm{F}_{\mathrm{jk}}$ - tensioning force in the band;

$\mathrm{F}_{\mathrm{f}}$ - the frictional force, $\mathrm{H}$;

$\mathrm{r}$ - radius of the rollers, $\mathrm{m}$;

$\mathrm{i}$ - gear reduction rate;

$\mathrm{K}_{\mathrm{red}}$ - reduction coefficient takes into account the impact of interacting masses previous to TF;

a - dissipation factor, characterizes the self-oscillation attention process in the system, $\mathrm{H} \cdot \mathrm{m} \cdot \mathrm{s}$;

$\mathrm{n}$ - rollers rotational speed;

$\mathrm{M}_{\mathrm{Rjk}}$ - moment of interacting masses static resistance.

For TF2 - the moment of deformation wave propagating from the TF1, for TF3 from the deformation wave propagating from TF1 and TF2, for TF4 - from the deformation wave propagating from TF1, TF2 and TF3.

Resistance module of electric drivers TF No3 and No4. as well as TA are described by equations similar to (2) with taking into account the influence of the interaction of the respective masses from the neighboring units.

For the simulation CAU electric drives the software package MATLAB 7.0. with extension Simulink was applied. Sampling simulation time and discrete-time signals processing were applied when the numerical integration of the large number of dynamic sub-systems with constant time significantly different from each other.

At the third stage the sequential iterative debugging of the first-level models was made, then of models of subsystems of second level and CAU electric drives. Adequacy of models is accomplished by comparing the results of multiple implementations obtained when oscillographic testing with the results of simulation experiments. We have achieved the convergence of simulation results with the results of oscilloscopic operation of CAU electric drives in regular modes with an accuracy of $10-15 \%$ which is sufficient for engineering applications in the process of debugging. Actual values of elasticity and plasticity of the treated metal and dissipation, active resistances and electric drivers' parameters of the magnetic system were specified and defined in the process of models iterative debugging. All changes were included in the models. During this the strip elasticity in the model is successively reduced in TF1 and TF2 and further increased in TF3 and TF4 in accordance with temperature conditions of heat treatment.

The adequacy assessment of the studied model was carried out on measurements of the actual system and on the results of the experiment on the model in accordance with Carl Pearson's chi-squared test for TF electric drive (Schenk, 1972). According to calculations, when the significance level $\alpha=0,10$, the number of measurements in the series $m=7$, the number of normal distribution constants $s=2$ and the number of freedom degrees $q=5$, criterion $\chi^{2}=0,582>0,10$, which indicates that the model is adequate to the object. By the similar methods debugging of the system model of the existing CAU interconnected electric drive in design modes of the unit operation was performed. This 
model was the starting point for the modernization of CAU electric drivers (Breido \& Sivyakova, 2008; Sivyakova, 2005).

The evaluation of sub-models subsystems was used to evaluate the adequacy of CAU electric drive model. Fisher criterion was used to assess the adequacy of the small samples (Schenk, 1972). For $n=6$ measurements, $m=2$ series, the number of freedom degree $\mathrm{q} 1=5$ and $\mathrm{q} 2=6$ the experimental value of the criterion is less than the table $\mathrm{kpe}=1,2<\mathrm{kft}=5,0$. Consequently, model obtained with $95 \%$ confidence coefficient describes the simulated process. Analysis of the oscillograms of simulation modeling results and statistical fitting criteria has shown, the model describes adequately with sufficient accuracy, dynamic processes occur in TF electric drivers. Error of simulation does not exceed $10 \%$ (see. Fig. $2 \mathrm{a}$ and $2 \mathrm{~b}$ which shows one implementation obtained when oscillographic testing and simulation modeling). When developing the model and carrying out the experiments only the low- frequency component was evaluated. The delay of propagation of elastic oscillations forces in different TF tambours identified during the oscillographic testing was confirmed.

Then structural and parametric optimization of electric drives of TF chambers was performed. It has been established that the TF chambers current regulator is insufficiently effective for controlling the strip tension under dynamic conditions (Breido, 2005; Breido \& Sivyakova, 2006). It is proved that the adjustment of regulators should be performed in speed function of the initial tension and rigidity of the strip. Moreover, by reducing the speed magnification factor of the regulator should reduce and the time response of the proportional plus reset controller should increase. The TF electric drive structure closed by negative feedback along the load current and the positive feedback on the speed derivative was synthesized. A distributed tension adjuster providing the compensation of friction losses during the strip movement on the basis of electric drives of TF chambers closed by load currents with the PI controllers for floating tension control was proposed.

For damping of the elastic wave oscillations along the strip when it changed its velocity an additional positive feedback according to speed derivative is introduced. It is proved that under condition $K_{d}=2 T_{m} K_{c s}$, where $K_{d}$ - transmission coefficient of the differentiating element; $T_{m}$ - mechanical time constant of the equivalent $T F$ drive, $K_{c s}$ - current sensor transmission coefficient, the combination of positive feedback according to the derivative speed and the negative feedback according to the current is equivalent to negative feedback according to the derivative tension forces with a firstorder filter (Breido \& Sivyakova, 2006). For the practical implementation the additional signal from the power-up sensor of given PR4 electric drive moment (leading mechanism of CAU) on the current controller inputs of TF electric drives has been introduced in the system. This signal is proportional to the specified dynamic moment, but it does not contain the clutters typical for speed signal sensor. The parameters of the regulators adjustment of TF electric drives chambers have been determined. Application of distributed tension adjusters on the basis of TF electric drives has allowed us to implement smooth starting of the unit.

The results of simulation experiments showed that the overshoot, i. e. dynamic stresses in the strip were decreased from $21 \%$ to $2 \%$. After debugging the system on the model the electric drives were put into operation as part of CAU. The modernization 
raised the speed of metal heat treatment from $2,5 \mathrm{~m} / \mathrm{s}$ to $8 \mathrm{~m} / \mathrm{s}$ with minimal dynamic loads in the strip (Breido \& Sivyakova, 2007).

\section{Modernization of the twin-engine electric drive mechanism of main hoist of the crane foundry production}

The electric drive of mechanism of the main lifting (ML) foundry crane by carrying capacity 420/100/20 tons of steel continuous casting department of converter shop of JSC "ArcelorMittal Temirtau" has two asynchronous short-circuit motors with $200 \mathrm{~kW}$ capacity, equipped with two frequency converters with vector control, and two horizontal type gears. Cinematic scheme of the main lifting of this mechanism is presented in Fig. 5.

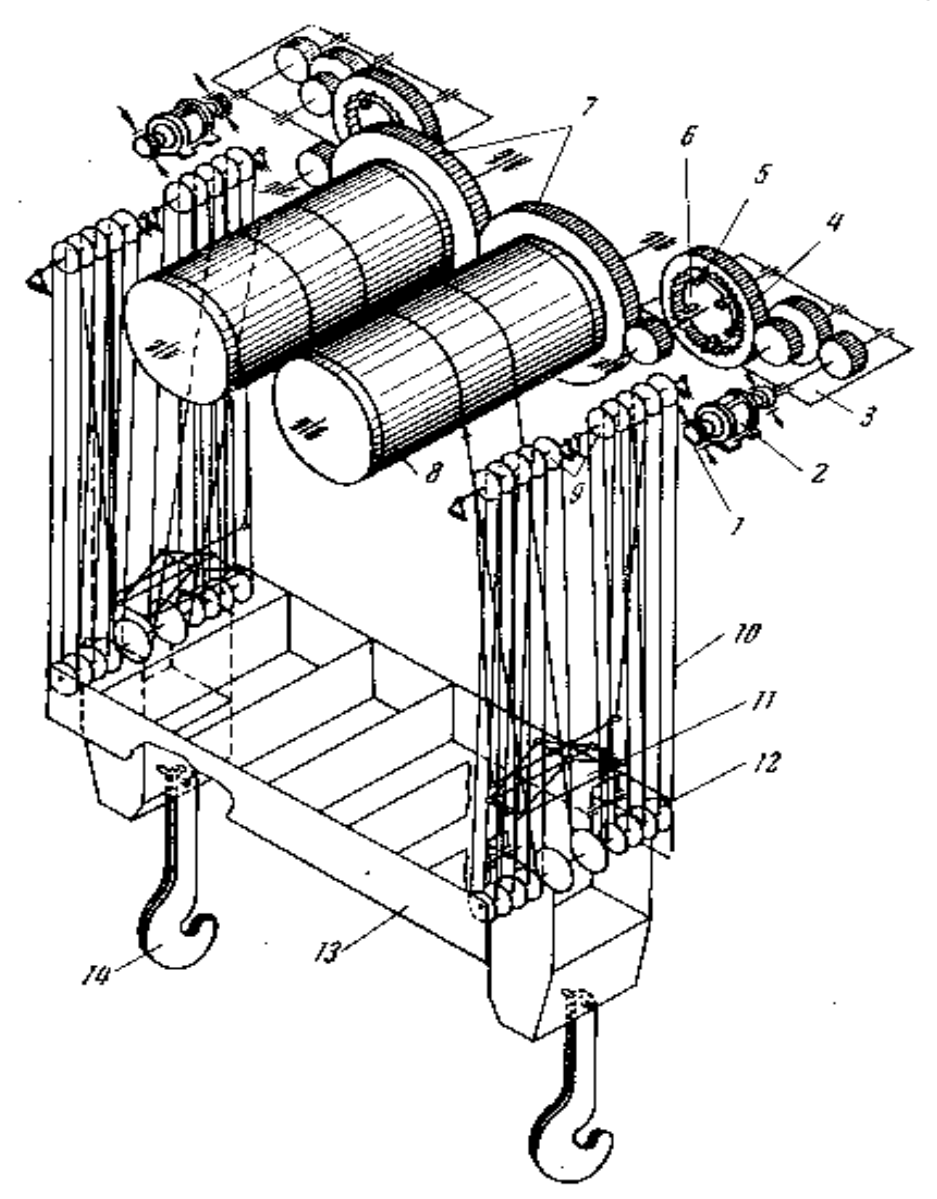

1 - brake; 2 - electric motor; 3 - reducer; 4 - slow-speed gear wheel; 5 - internal disk, 6 - pawl ratchet mechanism; 7 - drum gear wheels; 8 - cargo drums; 9 - upper immobile units; 10 - branches of the hoisting ropes; 11 - lower mobile units; 12 balancers; 13 - traverse; 14 - big hooks.

Fig. 5. Mechanism of the main lifting foundry crane

Inconsistency of the work of electric drives mechanism ML was found in the process of setting up and operating, which led to an increase in vibration activity and accelerated wear of expensive gears. The imbalance of moments between the drive in 
static and dynamic modes of operation has reached $20-45 \%$, so it had to reduce the working speed and productivity of the crane does not exceed $40 \%$ of the project.

The objective of the twin-engine mechanism modernization of foundry crane ML was to improve load balancing system (LBS). In addition, it was necessary to create a system of crane emergency management in case of the motors failure or converters.

There are Simovert Leadingdrives VC converters and programmable controller Simatic S7-300 in electric drive. Existing LBS was built on a scheme "leadingconducted". The basis of this scheme is the principle of transmission of assignment the controlled variable from "leading" drive, operating in the vector for speed control (SVC-leading), in the "conducted" drive, operating in direct torque control (DTCconducted), that provides moments' alignment. The speed reference signal is applied only to the leading drive (leading drive), in accordance with which, as well as the load moment the control system (CS) generates converter, an electromagnetic torque required for full compensation slip of the asynchronous motor (Breido \& Gurushkin, 2008).

This system does not take into account the specificity of emergency equipment regimes, shaft breakage of one of the drives or a converter failure, which leads to emergency operation of work, since if there is an accident in the leading drive CS by conducted drive, working in Direct Torque Control (DTC) mode, it receives the minimum value the specified moment, equal to idling of asynchronous electric drive of leading drive. Furthermore, there are additional fluctuation moments in the process of closing and opening gaps in reducers.

In the first stage of modernization there was oscillography in all normal modes of operation. There are not sensors of moments in the mechanical part, and although in the system of vector control on a crane, there are identified signals of electromagnetic torque for the electric drives, information needed to build an adequate model of the electric drive and it is not enough. It is impossible to determine the actual value of the stator resistance, flux linkage, the rigidity of mechanical characteristics of electric drives. It is not possible to determine the elasticity and clearances in reducers. Physical model of electromechanical system of the unit was created to determine the lacking mechanical properties.

Physical model (stand) contains electric drives, similar to those used on the crane, but significantly less power. Stand contains two short-circuited asynchronous electric drives with $3 \mathrm{~kW}$ capacity; one load asynchronous drive $11 \mathrm{~kW}$; three Simovert Leadingdriver VC converters; controller SIMATIC S7-300; load devices; speed sensors, etc. The mechanical part is modeled couplings having adjustable gaps. Electric drive is used as the load, which operates in generator and motor modes (Breido \& Gurushkin, 2009). The structural scheme of probationary stand is presented in Fig.6.

Results of oscillography of the crane operation electric modes are used to assess the similarity of the physical model. In this case no less than 10 implementations were recorded for each of the modes. 


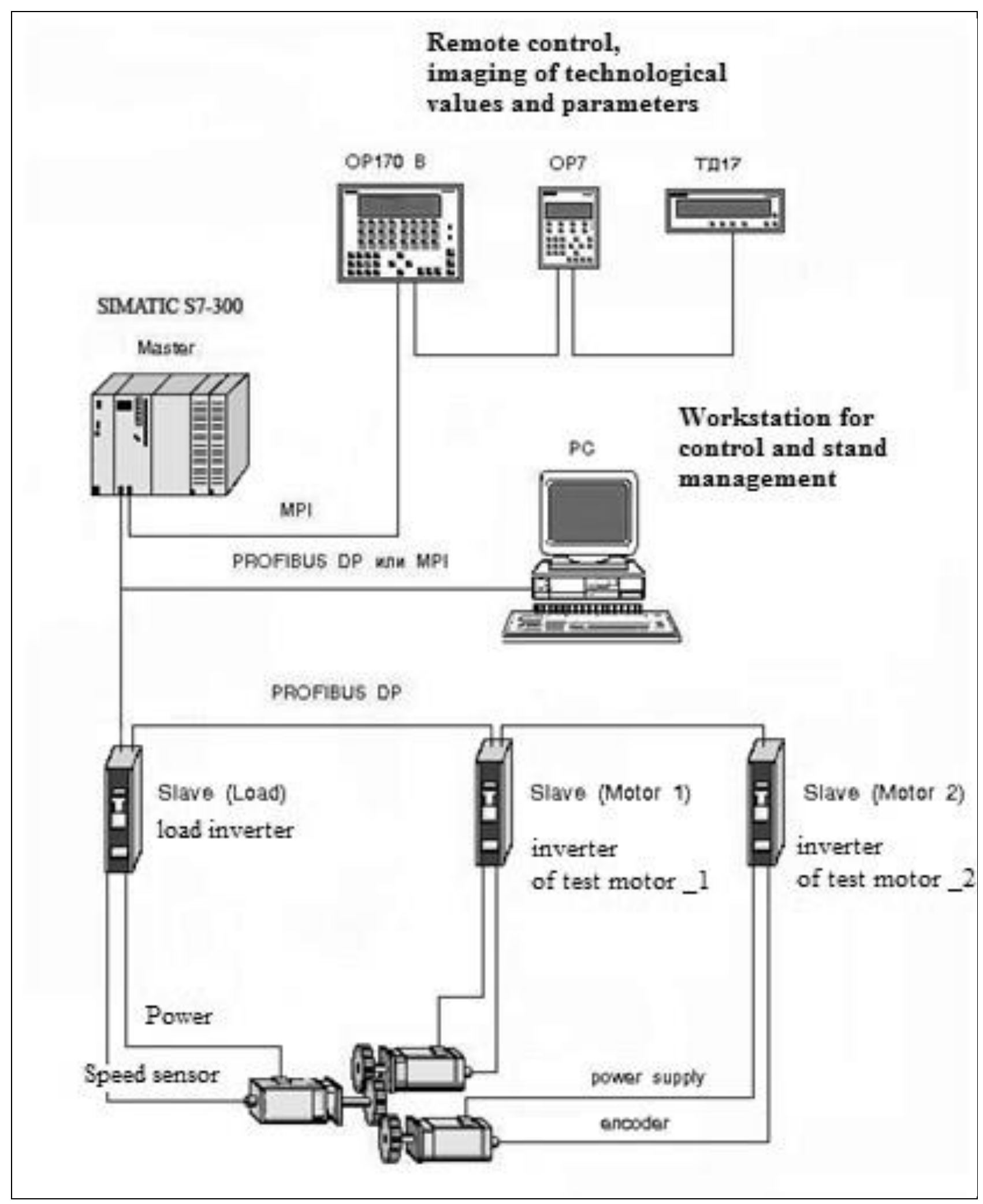

Fig. 6. Structural scheme of probationary stand

Stand tests together with simulation modeling were performed for the construction of the mechanical characteristics. This combination is possible to supplement the missing data on the research results on simulation model. Data of parameters equivalent circuit were used for debugging of simulation model, obtained in the course of the experiment. The difference between the basic observed values on 
the model and in the electric drive of the crane (speed, current and torque) does not exceed $8 \%$.

The combination of simulation and stand researches has allowed to identify the causes of uneven load distribution in static and dynamic modes. It was ascertained on the physical model (stand) that the main causes of imbalance moments in static and dynamic modes of operation in the system of electric drive taken along as the "leading - conducted" principle are not identical in parameters CS action of the speed feedback, and additional static and dynamic disturbances caused by the presence of gaps and elasticities in the mechanical part of the drive.

Installer of contour intensities (II) of a speed control generates in dynamics for each engine its individual predetermined rate of speed change reference signal and torque, depending on the parameters of the engine and set the parameters of the transition process. There is a division of the drive system "pulling" and "conducted" parts in a different rate of acceleration. And drive, which has formed tachogram of acceleration with a higher acceleration rate, takes the most load, and with a significant mismatch due to the feedback action in speed, there is a transition of "conducted" drive in generator mode. This separation takes place in a dynamic mode of operation and then stored in a static (Breido \& Gurushkin, 2008).

It has been established that the principle of the action LBS should be based on the work of both converters by the scheme master-master ("leading-leading"). This concept is based on the principle of an independent monitoring and control of each drive (vector control mode for both drives speed). In this case work of both drives must be coordinated and balanced by the presence of an additional contour of harmonization and alignment of moment's system unit.

In this case, both drives operate in the "leading" mode (master), and it does not matter if it is a mechanical connection break, because engine, remaining in engagement, at the expense of emergency power reserve takes all the load and troublefree process cycle ends or gradually reduces to a minimum the lowering speed of the bucket. This allows in the case of mechanical connection failure at any of the drives and in any part of the trajectory of motion safely complete technological cycle. In this case operation of actuators should be forcibly synchronized and coordinated. Furthermore, II harmonization also necessary due to existing in gear significant gaps because disconnection gap equivalent to breaking the mechanical connection and leads to different kinds of vibrations, oscillations and shock loads (Breido \& Gurushkin, 2009; Pankratov et al., 2014).

Designed algorithm of operation LBS unit, based on the calculation and making corrective changes in process of the value formation of the total output torque of one of the actuators and shown in Fig. 7.

Here $\mathrm{Te}_{8}$ and $\mathrm{Te}_{9}-$ moments drive $\mathrm{ML}_{8}$ and $\mathrm{ML}_{9}$ respectively; $\mathrm{T}_{\text {add }}$ - additional correction value of the moment; $\mathrm{T}_{\Sigma 8}$ - total torque setpoint ML8 engine; $\mathrm{T}_{\mathrm{set}^{*}}$ - torque setpoint. 


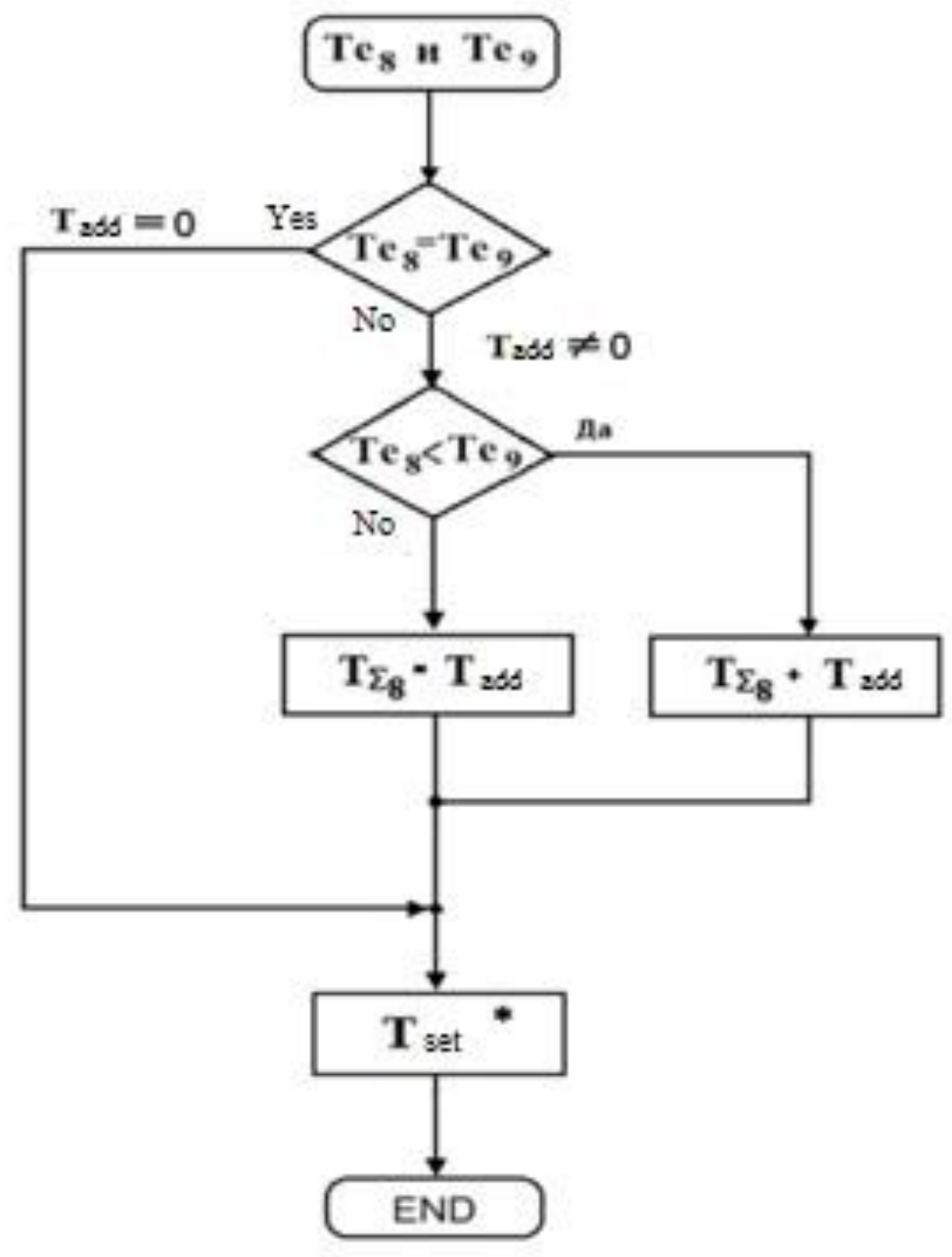

Fig. 7. Algorithm of LBS work

Working off and tests, the alarm system on the crane is not possible, because of the high risk, so all the experiments were carried out at the research stand. Figure 8 shows graphs of uniform load distribution in the cargo shutter mode used LBS "leading-leading" and simulated mechanical connection failure in Simulink.

Then LBS has been tested in descent mode and lift the bucket without metal and with metal. A uniform distribution of load is obtained between the motors in all of these modes. There is a simulation of mechanical failure connection in the load descent mode. This fact took place in the course of the crane operation to modernize. It did not exceed $2 \%$ in dynamic and static modes during the experiment on the stand imbalance of moments.

After breaking the mechanical connection engine, remaining engaged, it takes all the main load according to the set speed. A series of technological control lifting cycles (full) and descent (empty) casting ladles were executed on the mechanism ML of foundry crane. They reached $17,6 \%$ in the dynamics and $45,4 \%$ in static mode when using system "leading - conducted" without LBS use, during the descent ladle imbalance of moments (see Fig. 9). 
Breido, I.; Sivyakova, G. \& Gurushkin, A.: The Modernization of the Multimotor E...

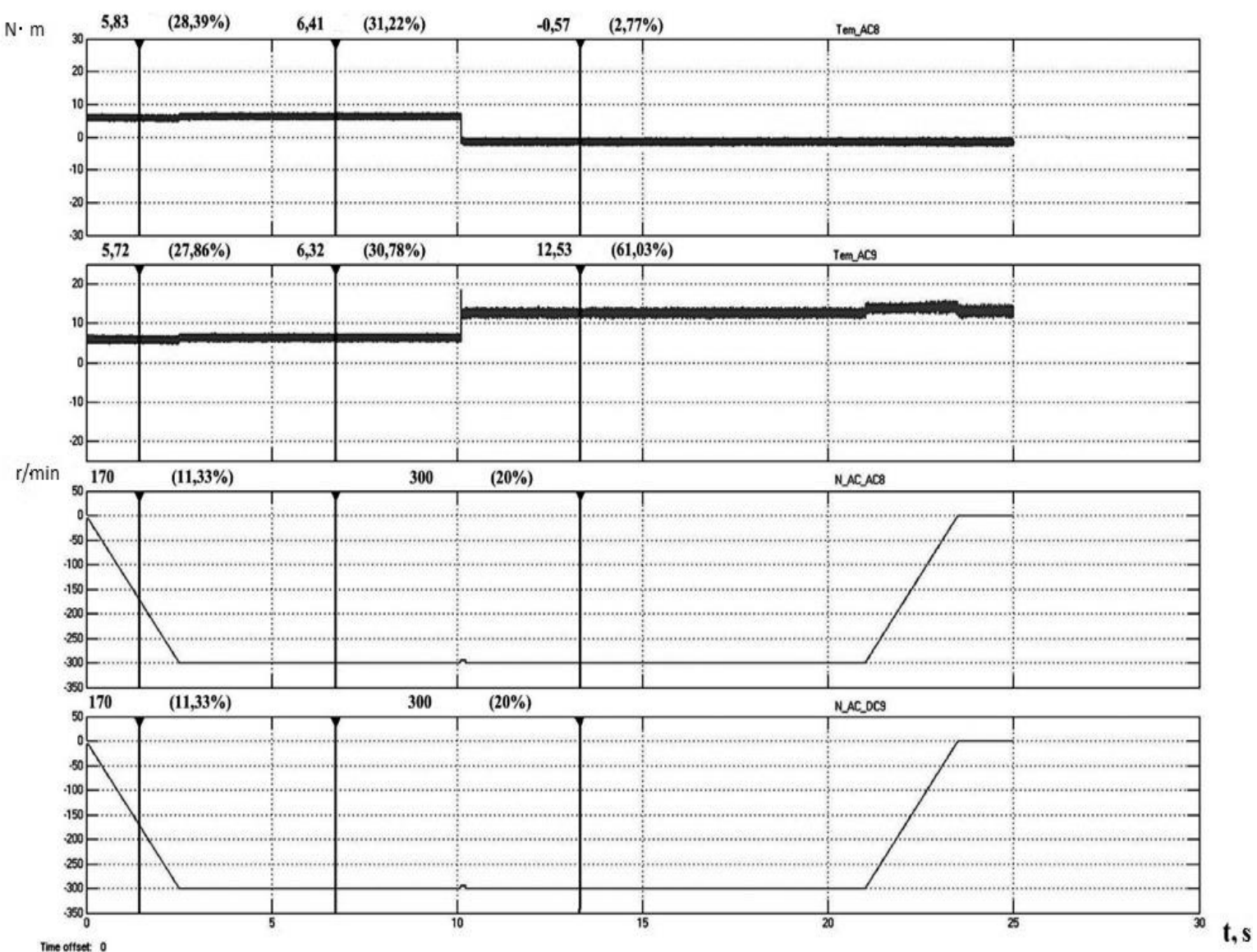

Fig. 8. Uniform load distribution in the cargo shutter mode using the LBS "leadingleading" and simulated mechanical connection failure (Simulink)
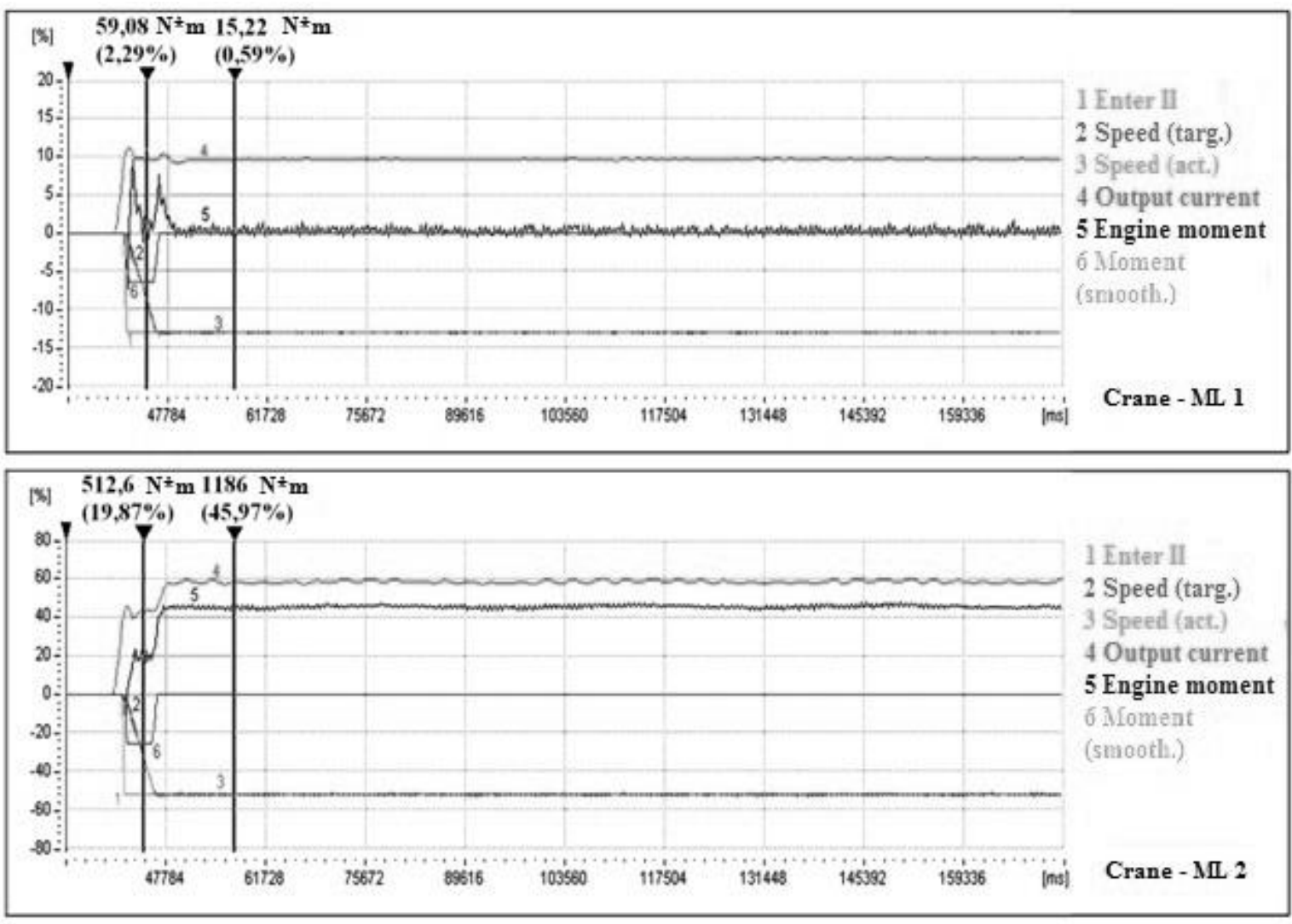

Fig.9 The descent of ladle weighing 108 tons without using LBS 
Imbalance moments in "leading-leading" system does not exceed 1-2\% during the descent, which confirms the high quality of LBS. Figure 10 shows the oscillogram of lowering ladle weighing 108 tons with "leading-leading" system. Analysis of obtained results showed that the proposed LBS can significantly improve the quality of static and dynamic modes operation, as well as to eliminate the lack of "leading-conducted" system - the inadmissibility of breaking the mechanical connection with the emergency operation and dynamic overload in the circuit-breaking gaps.

Productivity of crane in this case has increased twice by increasing its operating speed (Breido \& Gurushkin, 2009).

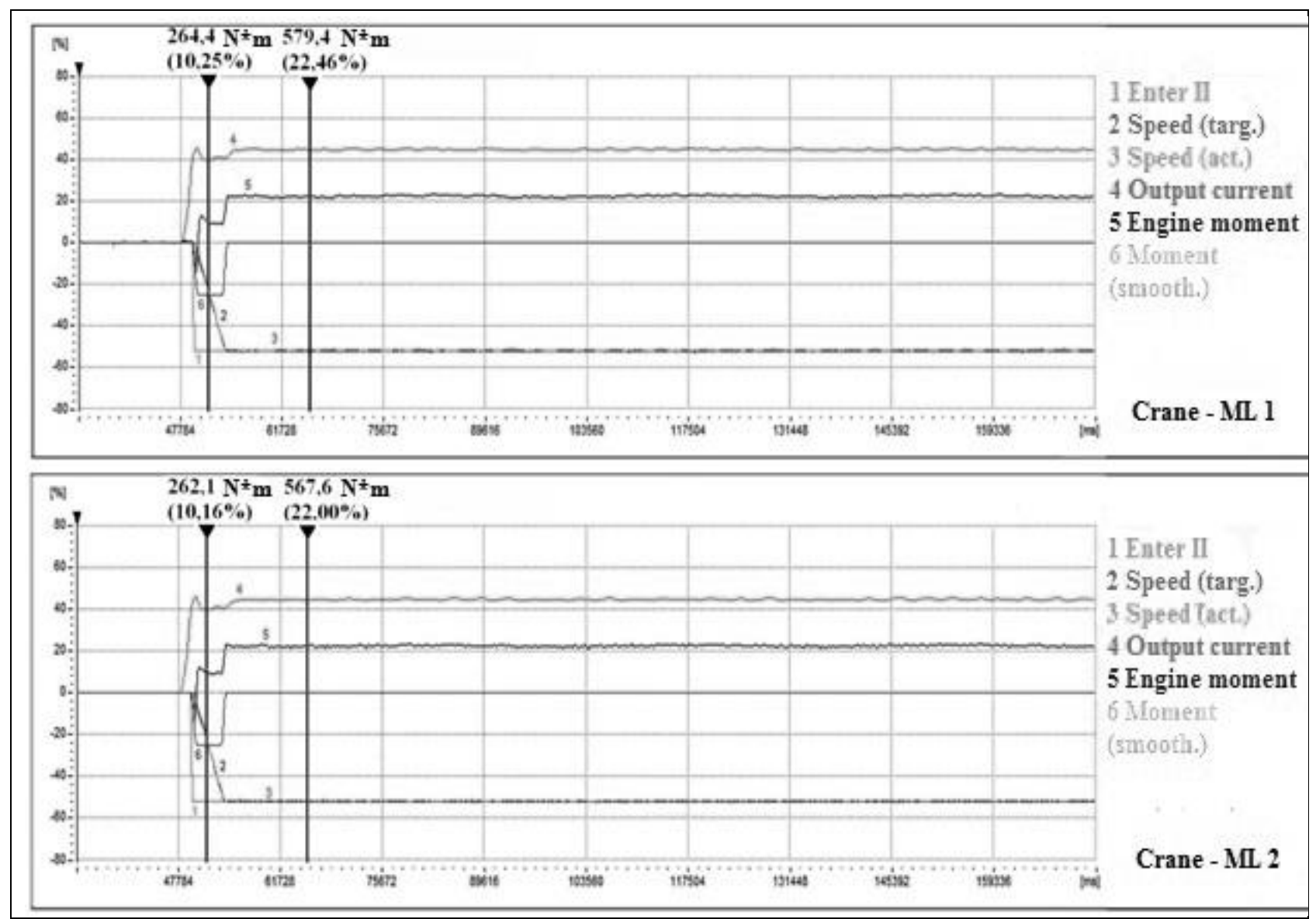

Fig. 10 The descent of ladle weighing 108 tons with using LBS

\section{Conclusions}

Authors' developed methodology is combining simulation and physical modeling with experimental researches carried out in the process of working modes, where part of the parameters is to produce adequate mathematical models of electromechanical systems is determined. It allowed to obtain a number of new results.

A hierarchical three-level mathematical model of the interconnected through processed metal multi-motor electric drive was designed for CAU. Model takes into account changes in the elastic properties of the strip in the continuous heat treatment, as well as the distribution of elastic strain waves along and against the direction of traffic lanes. The technique of equivalent related metal band of multi-motor electric drives of tower furnaces was suggested, as well as consistent technique of iterative 
debug model elements, subsystems and systems of CAU electric drives and their adequacy were ensured.

The structure of the interconnected CAU electric drive was synthesized containing distribution control tension on the basis of the group electric drives tower furnaces, closed positive feedback from a derivative given rate (dynamic torque) and negative - on the load current.

Regulator settings of tower electric drives furnaces in the speed function were established, the initial tension and stiffness of metal, supplying the dynamic forces decreasing in the line when modifying its speed. The results of simulation experiments showed that the overshoot, i. e. dynamic stresses in the strip were decreased from $21 \%$ to $2 \%$. The system debugging on the model and made on its basis modernization has provided raising the speed of metal heat treatment from $2,5 \mathrm{~m} / \mathrm{s}$ to $8 \mathrm{~m} / \mathrm{s}$ with minimal dynamic loads in the strip.

For electric drive of foundry cranes proposed methodology allowed to identify the causes of uneven load distribution between the motors in dynamic modes of the control system constructed in accordance with "leading-conducted" principle and its inconsistency with the requirements of safe descent ladle in event of a failure in one of the gear or motor.

It was found that the main reason for the imbalance moments occurring during start-up is not identical output characteristics of the installer intensities, conditioned by the feedback effect on speed, resulting in one of the motors acts as a generator, and the other remains in the motor mode and reboots. The main reason for the imbalance moments is opening and closing gaps in dynamic modes.

A structure of the control system for "leading-leading" basis was proposed, the algorithms of its work and system of disaster management of the crane were designed. The imbalance of the moments is decreased to $1-2,5 \%$ from $45 \%$ in static and $20 \%$ in dynamic for casting crane, and the crane productivity has doubled.

The developed methodology can be used for upgrading or designing interconnected through the processed material or mechanical connection multimotor electric drives units and technological lines, with similar principles of operation in the metallurgy and other industry branches.

\section{References}

Borovik, A. (2010). Multiengine Electric Drive of Pipe Cold Rolling Mill. Russian Electrical Engineering, 2010, Vol. 81, No. 3, (March 2010) pp.126-130, ISSN 10683712

Breido, J. (1998) Development of a Mathematical Model of the Interconnected Towertype Furnaces Electric Drives of the Continuous Annealing Unit. Electrotechnical systems and complexes, No 3, (September 1998) pp. 86-90

Breido, J. (2005A) Development of the Electric Drive Model of Continuous Annealing Unit Pinch Rolls, Bulletin of Pavlodar State University, Ser. "Energy", No4, (December 2005) pp. 76-84, ISSN 1811-1858

Breido, J. (2005B) Development of the Simulation Model of the Interconnected CAU 
Electric Drive. Bulletin of MTU "Kharkov Polytechnic Institute", Ser. "Electrical engineering, electronics and electric drive", No45, (September 2005) pp. 145-146, ISSN 2079-3944

Breido, J. \& Sivyakova, G. (2006) Structural Optimization of the Electric Drives Chambers of Tower-type Furnace Continuous Annealing Unit. Proceedings of KSTU University, No4, (December 2006) pp.78- 81, ISSN 1609-1825

Breido, J. \& Sivyakova, G. (2007) Parameter Optimization of Tension Adjusters of Tower-type Furnaces Electric Drives. Proceedings of KSTU University, No 1, (March 2007) pp. 85-87, ISSN 1609-1825

Breido, J. \& Gurushkin, A. (2008) The Test Laboratory Stand for Researches, Tests and Commissioning of the Frequency-controlled Asynchronous Electric Drive. Drive technology, No6, (December 2008) pp. 52-59, ISSN 2077-6411

Breido, J. \& Sivyakova, G. (2008) The Simulation Model of the Interconnected Electric Drives of Technological Part of the Continuous Annealing Units. Proceedings of the universities. Ser. "Electromechanics", No2, (March - April 2008) pp. 61- 64, ISSN 0136-3360

Breido, J. \& Gurushkin, A. (2009A) Load Distribution in Electromechanical Systems with Multiimpellent Frequency-controlled Electric Drive. Proceedings of the University, No2, (June 2009) pp. 72-75, ISSN 1609-1825

Breido, J. \& Gurushkin, A. (2009B) The Study of Principles Load Distributions in Electromechanical Systems with Multiimpellent Frequency-controlled Electric Drive. Drive technology, No3, (June 2009) pp. 29-33, ISSN 2077-6411

Breido, J. \& Gurushkin, A. (2009C) Combined Methods of Designing and Setting up the Twin-engine Frequency-controlled Asynchronous Electric Drive. Drive technology, No2, (March - April 2009) pp. 28-33, ISSN 2077-6411

Breido, J. \& Gurushkin, A. (2009D) Development of the System of Load Balancing for Multiimpellent Frequency-controlled Electric Drive of Mechanism the Main Lifting of Foundry Cranes of Metallurgical Production. Drive Technology, No6, (December 2009) pp. 40-50, ISSN 2077-6411

Breido, J. (2013) The State and Prospects of Development of the Interconnected Multi-Motor Semiconductor Electric Drives, Chapter 08 in DAAAM International Scientific Book 2013, Katalinic, B. \& Tekic Z. (Eds.), pp.193-212, DAAAM International, ISBN 978-3-901509-94-0, ISSN 1726-9687 Vienna, Austria

Breido, J.; Sivyakova, G. \& A. Guruchkin (2013) The State and Prospects of Development of the Interconnected Multi-motor Semiconductor Electric Drives, Chapter XVI in Chalanges for the Future - Industrial Engineering, Zelenovic, L. \& Katalinic, B. (Ed.), pp.311-330, Faculty of Technical Sciences, ISBN 978-86-7892579-5, Faculty of Technical Sciences (Novi Sad, Serbia), DAAAM International (Vienna, Austria) and Fraunhofer IAO (Stuttgart, Germany) 
Breido, I.; Sivyakova, G. \& Gurushkin, A.: The Modernization of the Multimotor E...

Faizrakhmanov, R.; Volodin, V.; Sharonov, A. \& Polevshchiko, I. (2015) Analysis of Perspective Control Methods of a TwoEngine Electric Drive. Russian Electrical Engineering, Vol. 86, No. 11, (November 2015) pp.625-629, ISSN 10683712

Frederick L. \& Dubey Gopal K. (1997). AC Motor Traction Drives - A Status Review. Sädhanā, Vol. 22, Part 6, pp. 855-869 () Printed in India

Medvedev, Yu. \& Kuznetsov, V. (2011) Energy Calculation of Multimotor Electrohydraulic Drives with Random Parameter Variation. Russian Engineering Research, Vol.31, No. 1, (January 2011) pp. 6-12, ISSN 1068798X

Pankratov, V.; Kotin, D. \& Vdovin, V. (2014). A Doubly Fed Induction Motor Drive of a Mine Hoisting Plant. Russian Electrical Engineering, Vol. 85, No. 12, (December 2014) pp. 709-712, ISSN 10683712

Polyakov, A.; Polyakov, K.; Trykov, R.; Seryakov, I.; Pavlov, N. \& Bordovskaya T. (2009). Fibre Chemistry, Vol. 41, No. 4, (July-August 2009) pp.35-37

Polyakov, A.; Polyakov, K.; Pavlov, N.; Seryakov, I. \& Kozlova L. (2010). Fibre Chemistry, Vol. 42, No. 1, (January-February, 2010) pp. 55-58

Rassudov, L. (1987) Electric drives with distributed parameters of mechanical elements, Energoatomisdat, Leningrad branch, Leningrad

Schenk, H. (1972) Theory of Engineering Experiment, Mir, Moscow'

Sivyakova, G. (2005) The Simulation Model of the Automatic Control System Pulling Mechanisms, Proceedings of the University, No3, (September 2005) pp.71 -72, ISSN 1609-1825

Tarasov, V.; Spirov, A.; Yakovlev, V.; Sergienko, R.; Radievskii, S.; Krasil'nikov, A. \& Sizyakin, A. (2008). Comprehensive Updating of the Multimotor Electric Drive for Type PN-500 machines. Fibre Chemistry, Vol. 40, No5, (SeptemberOctober 2008) pp.57-60

Vydrin, V. (1984) Automation of Rolling Manufacture, Metallurgy, Moscow Zyuzin, V. (1991) The Theory of Rolling, Metallurgy, Moscow 